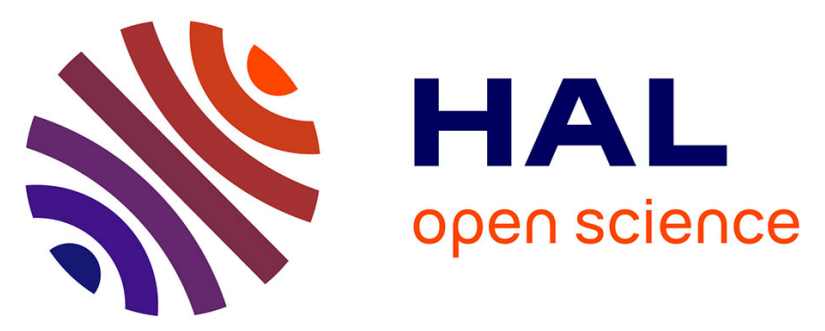

\title{
Planar Magnetic Components in More Electric Aircraft: Review of Technology and Key Parameters for DC-DC Power Electronic Converter
}

Jean Sylvio Ngoua Teu Magambo, Reda Bakri, Xavier Margueron, Philippe Le Moigne, Arnaud Mahe, Stephane Guguen, Taoufik Bensalah

\section{To cite this version:}

Jean Sylvio Ngoua Teu Magambo, Reda Bakri, Xavier Margueron, Philippe Le Moigne, Arnaud Mahe, et al.. Planar Magnetic Components in More Electric Aircraft: Review of Technology and Key Parameters for DC-DC Power Electronic Converter. IEEE Transactions on Transportation Electrification, 2017, 3 (4), pp.831 - 842. 10.1109/TTE.2017.2686327 . hal-01886549

\section{HAL Id: hal-01886549 \\ https://hal.science/hal-01886549}

Submitted on 2 Oct 2018

HAL is a multi-disciplinary open access archive for the deposit and dissemination of scientific research documents, whether they are published or not. The documents may come from teaching and research institutions in France or abroad, or from public or private research centers.
L'archive ouverte pluridisciplinaire HAL, est destinée au dépôt et à la diffusion de documents scientifiques de niveau recherche, publiés ou non, émanant des établissements d'enseignement et de recherche français ou étrangers, des laboratoires publics ou privés. 


\title{
Planar Magnetic Components in More Electric Aircraft: Review of Technology and Key Parameters for DC-DC Power Electronic Converter
}

\author{
Jean Sylvio Ngoua Teu Magambo, Reda Bakri, Xavier Margueron, Member, IEEE, Philippe Le \\ Moigne, Member, IEEE, Arnaud Mahe, Stephane Guguen and Taoufik Bensalah
}

\begin{abstract}
The More Electric Aircraft (MEA) has motivated aircraft manufacturers since few decades. Indeed, their investigations lead to the increase of electric power in airplanes. The challenge is to decrease the weight of embedded systems and therefore the fuel consumption. This is possible thanks to new efficient power electronic converters made of new components. As magnetic components represent a great proportion of their weight, planar components are an interesting solution to increase the power density of some switching mode power supplies. This paper presents the benefits and drawbacks of high frequency planar transformers in DC/DC converter, different models developed for their design and different issues in MEA context related to planar's specific geometry and technology.
\end{abstract}

Index Terms - MEA; power density; power converters; planar transformer; high frequency losses; parasitic elements.

\section{INTRODUCTION}

Since the beginning of aviation, engineers have investigated solutions to generate and control electrical power aboard airplanes [1]. Currently, with More Electric Aircraft (MEA), this topic mobilizes avionic equipment manufacturers with the aim to increase the available power in new aircraft generations [2]. For the last ten years, the power supplied by electrical systems has been multiplied by a factor of 10 (Fig. 1).

The MEA has ambitious objectives in the coming years such as reducing fuel consumption and the emissions of noise and gas $\left(\mathrm{CO}_{2}, \mathrm{NO}_{\mathrm{x}}\right)$. In Europe, avionics manufacturers mutualize their skills around different projects (Clean Sky 2 [3], Genome [4]) to meet these objectives. Some topics developed in MEA projects deal with the replacement of

Manuscript received October 6, 2016; revised January 28, 2017; accepted March 7, 2017

J .S. Ngoua Teu Magambo, R. Bakri, X. Margueron and P. Le Moigne are with Univ. Lille, Centrale Lille, Arts et Metiers ParisTech, HEI, EA 2697 - L2EP - Laboratoire d'Electrotechnique et d'Electronique de Puissance, F-59000 Lille, France (e-mail: jsylvio.ngouateu@ec-lille.fr; reda.bakri@ec-lille.fr;xavier.margueron@centralelille.fr; philippe.lemoigne@centralelille.fr).

A. Mahe, S. Guguen and T. Bensalah are with Thales AES, 41 Boulevard de la Republique, 78400 Chatou, France (e-mail: arnaud.mahe@fr.thalesgroup.com; stephane.guguen@fr.thalesgroup.com; taoufik.bensalah@fr.thalesgroup.com). hydraulic and pneumatic systems by electrical ones [5], with a trend toward dc solutions [6][7] or greener taxiing period [8][9] for example. Electrical systems have significant advantages such as gain of mass, energy rationalization, availability and maintenance costs [9].

More generally, electrical systems in aircraft relate to various electrical engineering domains from generation to power distribution, energy storage for emergency power supply or electrical loads. All these devices are connected through power converters: Inverters, rectifiers and choppers. Power electronic systems are needed with specific features due to aeronautic specifications: Harmonics, power factor, electromagnetic compatibility (EMC), efficiency, size, weight, harsh environment and isolation [10]. The latter characteristic is necessary for safety and reduction of EMC current [11]. This isolation function is usually made with high frequency transformer, included in power electronic converter.

Magnetic components, transformers and inductors, present an important issue that limits the integration of power converters. As a comparison, power train of static inverters achieve some $6 \mathrm{~kW} / \mathrm{kg}$ [12], while DC/DC converters with a high frequency transformer are rather below $2 \mathrm{~kW} / \mathrm{kg}$ [13]. However, when comparing a DC-DC converter with an isolated inverter, the results are not the same. In [14], the authors have shown that when using a planar transformer for both a DC-DC converter and a DC-AC inverter, the best power integration and the best efficiency were obtained for the DC-DC converter.

Although those magnetics limit the integration, they are still a key technology to improve power converters performances, in particular in MEA [15]. Indeed, historically, research on lighter transformers began with the first investigation of electrical power in aviation [16].

With the development of planar magnetic components (PMC), high frequency planar self and transformers became an interesting solution in $\mathrm{AC} / \mathrm{DC}$ or $\mathrm{DC} / \mathrm{DC}$ power converters to increase power densities [17]. Actually, increasing the frequency allows reduction of the principal inductance value and hence the core size, but true till a certain frequency limit only. Moreover, the low profile of PMC allows them having higher surface/volume ratio as compared to conventional 
magnetics, and therefore, have a better thermal behavior [17].

Planar magnetics are largely used in automotive for electric vehicles (EV) and more generally in embedded systems. Aeronautics and aerospace industries also investigate benefits provided by the use of new technology of PMC, especially with new constraints in onboard electrical systems.

This paper presents a review of planar technology and benefits that could be obtained with the use of such component in a MEA application. The aim is to discuss transformer key parameters which can help improving performances of a DC-DC converter and its integration. Based on a MEA power converter application, planar magnetic models available in literature are reviewed and analyzed in compliance with aeronautical specifications. The idea is to give readers a complete view of problematics even if models and analytical methods are not deeply developed in the paper. Finally, a planar transformer is designed in order to highlight different parameters and constraints previously reviewed.

The paper is organized as follows: In Section II, a DC/DC converter example serves as a reference to illustrate the interest of using high frequency planar transformers. Section III presents the issue of planar magnetics in MEA. Then the section IV focuses on the key parameters for efficient planar transformer in an aeronautical environment. In the final section, a planar transformer prototype is designed to illustrate steps and benefits of planar magnetics in MEA.

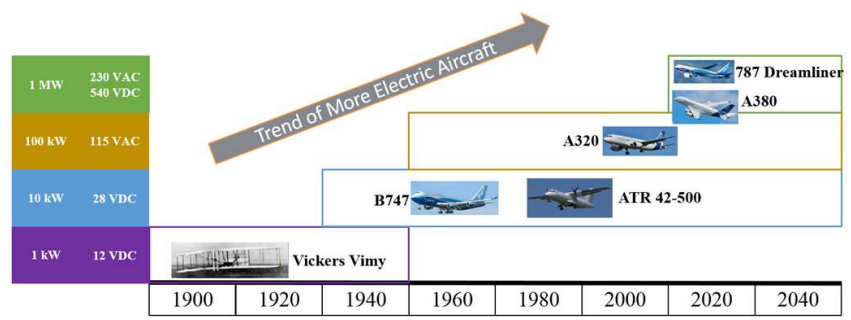

Fig. 1. MEA, throughout the ages

\section{A MeA APPliCATION: A DC-DC POWER CONVERTER}

Voltage and power flow in avionic systems are expanding with the development of new power electronic converters. Fig. 1 shows the increase of active power linked to the rise of voltage level. Till date, the trend is the use of two DC link of $\pm 135 \mathrm{~V}$ or $\pm 270 \mathrm{~V}$ respectively generated from a $115 \mathrm{Vac}$ or $230 \mathrm{Vac}, 400 \mathrm{~Hz}-800 \mathrm{~Hz}$ through a rectifier unit. The $\pm 270 \mathrm{~V}$ DC voltages enable to obtain the new standard $540 \mathrm{Vdc}$ which is known as the high voltage direct current (HVDC) link of new DC aircraft electric network. Fig. 2 shows an example of a power transfer from an $\mathrm{AC}$ generator to a $28 \mathrm{Vdc}$ storage battery. It could be noted that most of electric loads in avionics are designed for $28 \mathrm{Vdc}$ nominal voltage.

In the following, the aim is to present the study of a DC/DC converter. Such a converter can lead to substantial power density enhancement, reducing the size of the transformer and maintaining a good efficiency level.

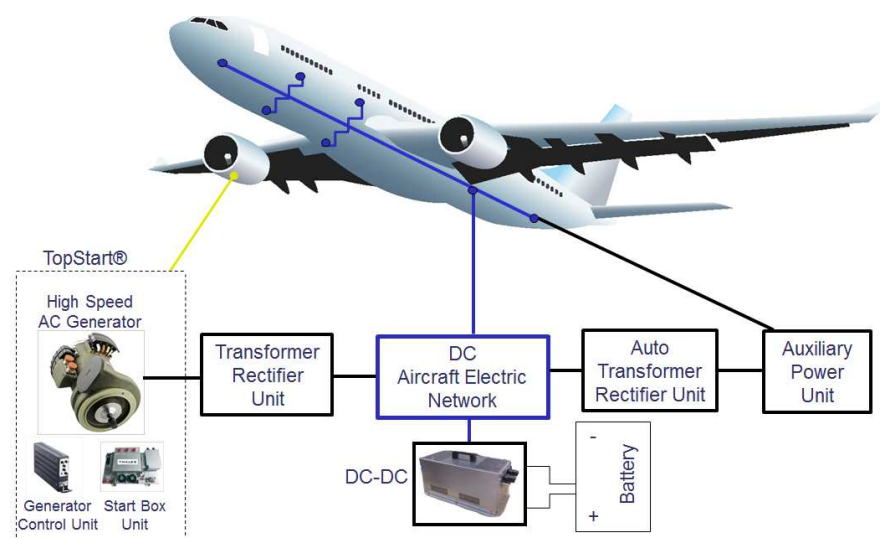

Fig. 2. Example of an Aircraft Electric Network with industrial power converters

\section{A. Example of Converters' Specifications: Triple Active Bridge Converter}

The converter under development is a three port DC/DC converter of few $\mathrm{kW}$. From the new 540V HVDC voltage, the two $28 \mathrm{~V}$ low voltage direct currents (LVDC) must be generated. One output is regulated to $28 \mathrm{Vdc}$ while the other one is connected to a $28 \mathrm{~V}$ battery. Actually, the converter has different operating modes and must be able to operate in buck, boost and buck-boost depending on external constraints. In case of an interruption of the HVDC bus, the LVDC battery side must be able to restart the input voltage or to generate the other 28V LVDC output. The regeneration of the DC bus is an important aspect and an interesting application when dealing with a DC-DC converter in MEA [18][19][20].

One structure which fits correctly these specifications is the triple active bridge (TAB) [21] as presented in Fig.3. The two LVDC outputs can also be put in parallel to generate the HVDC voltage, becoming a Double Active Bridge (DAB) converter. $\mathrm{DAB}$ and $\mathrm{TAB}$ architectures are well known in literature [22][23][24][25][26] but for MEA, such LVDC 28V application is a key challenge including the safety compliances.

The TAB is an isolated and bidirectional DC-DC converter which is composed of three full bridges, one input H-bridge and two output H-bridges (Fig. 3). Between input and output bridges, a high frequency transformer not only ensures the different operating mode (buck, boost...) but also the galvanic insulation of the converter. Note that in Fig. 3, the 3-winding high frequency transformer is represented with a leakage transformer [27]. This leakage transformer is useful when representing magnetic coupling between transformer's outputs and useless when this coupling is low.

With such topology and voltage levels, semiconductors are made of SiC MOSFET for the HVDC side and Si MOSFET for the LVDC side. The converter must operate with a switching frequency around few tens of kHz. Table I summarizes the converter's specifications. 


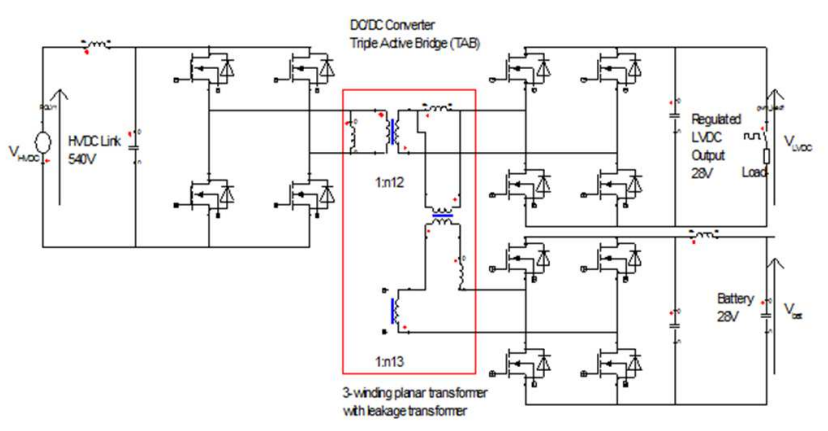

Fig. 3. TAB simplified electric diagram

TABLE I: Converter's electric specifications

\begin{tabular}{|c|c|}
\hline \multicolumn{2}{|c|}{ TABLE I: Converter's electric specifications } \\
\hline $\mathrm{V}_{\text {HVDC }}$ & {$[450 \mathrm{~V} ; 650 \mathrm{~V}]$} \\
\hline $\mathrm{V}_{\text {LVDC }}$ & {$[26 \mathrm{~V} ; 32 \mathrm{~V}]$} \\
\hline $\mathrm{V}_{\text {bat }}$ & {$[16 \mathrm{~V} ; 32 \mathrm{~V}]$} \\
\hline Transformer ratio & $17: 1: 1$ \\
\hline Leakage inductance (from primary side) $L_{k 1 i}$ & $30 \mu \mathrm{H}$ \\
\hline Fsw & {$[70 \mathrm{kHz} ; 150 \mathrm{kHz}]$} \\
\hline
\end{tabular}

To reduce the switching and conduction losses, an optimization on the control strategy is made to minimize the rms current through the components [22]. The basic control strategy commonly used is the phase-shift modulation (PSM) which consists in controlling all MOSFET with same duty cycles $(\mathrm{D}=0.5)$ delayed with a phase $\varphi_{1 i}(\mathrm{i}=2,3$ corresponding to the output bridges) between input and output bridges. These two setting parameters $\left(\varphi_{12}\right.$ and $\left.\varphi_{13}\right)$ allow to tune the power flow (1). This strategy can lead to good efficiency while operating around nominal conditions. For voltages higher than the nominal, others strategies such as alternative modulations can be privileged [23].

The control strategy which consists in minimizing the rms current is used not only to reduce switching losses but also allows reducing copper losses in the transformer because these losses are linked to the current. The control must also avoid DC current which could quickly saturate the magnetic core.

In order to minimize switching losses at the turn on, all full bridge legs are controlled with zero voltage switching (ZVS), helped by each MOSFET capacitance.

To simplify the study of the TAB, one output H-bridge can be considered as opened. Then, in the equivalent two port, with a PSM strategy on both full bridges, the power flow between the primary and one secondary winding (which is not opened) for example, is expressed as follows [26]:

$$
P_{1 i}=\frac{\varphi_{1 i}\left(\pi-\varphi_{1 i}\right) V_{1} V_{i}}{2 \pi^{2} F_{s w} L_{k 1 i}}
$$

With $\varphi_{1 i}$ the phase between primary winding voltage $V_{1}$ and secondary winding $i$ voltage $V_{i}, F_{s w}$ is the fundamental switching frequency and $L_{k 1 i}$ the leakage inductance between the two windings from primary side.

\section{B. Discussion on Power Density}

Regarding power considerations, this converter must be able to operate in a high temperature environment with a nominal efficiency of $94 \%$. The aim is to reach at least
$1.5 \mathrm{~kW} / \mathrm{kg}$ (or $1 \mathrm{~kW} / \mathrm{L}$ ) of power density.

The heatsink represents a non-negligible element because of its weight and size, and because MEA power converters are generally in a harsh environment [28]. Thermal performances impact the component's functioning (semiconductors, insulation, core...) and so the reliability of the converter. For example, Fig. 4 shows a 3D view of a prototype of the DC/DC converter, including planar transformer and inductor, with a heatsink placed on the two faces (top and bottom) of the PCB. Note that it is not a final optimized structure. Some adjustments have to be done regarding dimensions and the components' distribution.

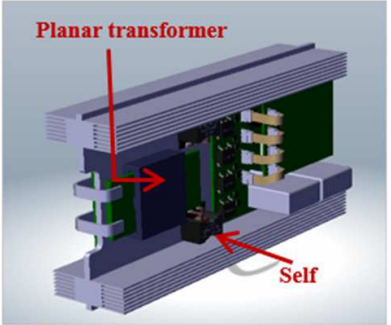

(a)

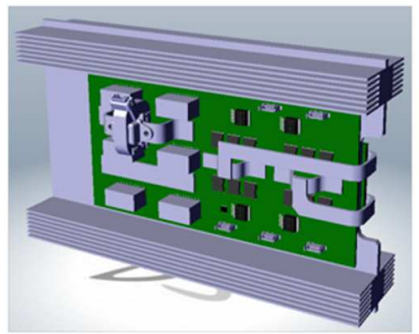

(b)
Fig. 4. 3D view of a prototype (a) HVDC side (b) LVDC side

\section{Toward the integration of magnetics for TAB converter}

Research has shown its interest for transformer's technology since the first generation of voltage in airplanes. Initially, transformers were designed for each embedded electric load, operating at the AC frequency of voltage generators and power network. Power density was not yet a topic of interest. Actually, with the development of power transistors and power converters, transformers and more generally magnetics have become key components for the achievement of high power density.

For the TAB converter, as it was introduced previously, the transformer leakage inductance has to be set to a specific value to obtain the nominal power value (1). Leakage inductances of planar transformers are known to be low [29], especially when a good efficiency of the transformer is required. Therefore, the value of the leakage inductance is lower than expected $\left(L_{k 1 i}\right.$ in Table I) at fundamental frequency. The difference could be completed either by adding a resonant self or a bus bar on winding connections. Both solutions increase size and weight of the converter.

Another specification for the TAB converter deals with the fact that both secondary windings can be set in parallel to transfer power to the HVDC side. As a consequence, leakage inductance values, between primary winding and secondary windings $\left(L_{k 12}, L_{k 13}\right)$ must be as close as possible to parallel both windings.

With such converter topology and specifications, the use of an efficient and lightweight high frequency transformer is mandatory. It can be noted that in power electronics, high frequency for PMC means from few tens of $\mathrm{kHz}$ to several hundred of $\mathrm{kHz}$. The high frequency range is rarely beyond $1 \mathrm{MHz}$ because of skin and proximity effects regarding magnetic core behavior, conductor's size and the conductors' arrangement chosen. 
Planar technology presents a lot of benefits for this kind of application but also some drawbacks. The expansion of PMC in MEA is constraint with the perfect control of some component's parameters.

\section{PlanAR Magnetics: IsSUES IN MEA}

\section{A. Generalities on Planar Components}

PMC are interesting alternatives to classic high frequency transformers [17]. Based on the combination of a low profile high frequency magnetic core and printed circuit board (PCB) or copper foil windings technology, PMC enable to obtain significant gain in terms of weight and size but also regarding electrical and thermal performances.

Planar magnetics presents some benefits as compared to traditional high frequency wound magnetic components:

- Low profile component.

- Lightweight.

- High power density.

- Good reproducibility based on winding's precision.

- Easy manufacturing for industrial and cost effective.

- Good thermal behavior [30] due to their surface/volume ratio.

- Low leakage inductance.

- Low AC copper losses due to the rectangular shape of the conductors.

On the opposite, some drawbacks can be listed:

- Restricted to high frequency use.

- Limited core size and shape.

- Limited power range, few $\mathrm{kW}$.

- Too weak leakage inductance value for some resonant converter applications.

- Penalizing parasitic capacitances.

- Longer mean turn length (MTL) and consequently higher DC resistances due to core shape.

- Complexity of wires connections in case of multilayers windings.

Some of these benefits and drawbacks don't have the same impact when dealing with MEA power converters. Let's now detail some topics to investigate how to use efficiently those advantages and how to circumvent those limits in MEA context.

\section{B. Planar Magnetic Cores}

Due to the industrial context, it is better to begin investigation using existing core on the market, otherwise it is necessary to control the manufacturing techniques and so, the prototyping cost can quickly increase.

The core size of a transformer is often chosen according to the magnetizing inductance desired and the desired active power through the area product of the core [31]. The typical planar core made of ferrite are given in Fig. 5: EE, ER, EQ and PQ [32][33][34].

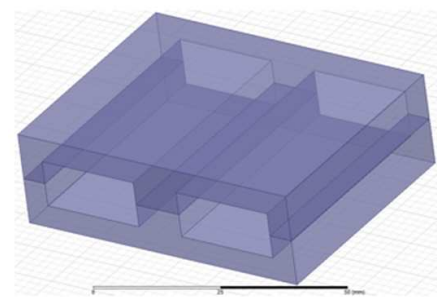

(a)

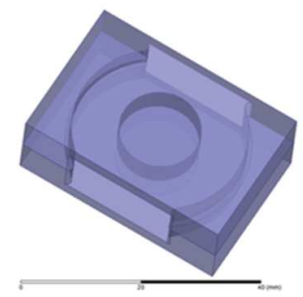

(c)

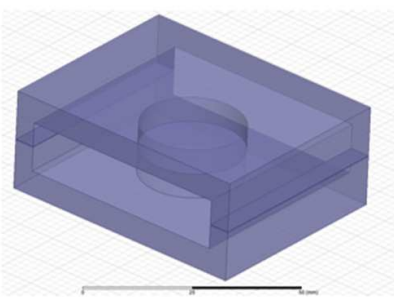

(b)

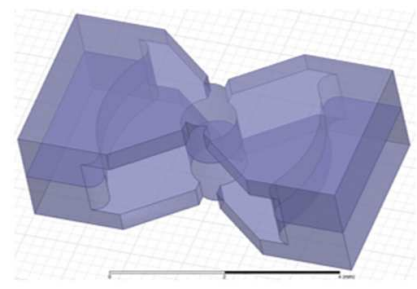

(d)
Fig. 5. Available planar core shapes: (a) EE (b) ER (c) EQ and (d) PQ

The EE shape requires straight windings while ER, EQ and PQ match with circular ones. The advantages of ER, EQ and PQ cores are their lower copper losses and parasitic elements thanks to the copper shape which reduce the mean turn length. In [35] the author has shown that a planar transformer with a PQ core leads to the best efficiency for an aircraft application.

Table II presents planar core size and weight for smallest and biggest core in each shape. The core volume represents the external dimensions and not the volume of material. Data are extracted from a manufacturer datasheet [32] but similar shapes and dimensions can be found with other core manufacturers [33][34]. As it can be seen in Table II, EE shape seems to have the best compromise between size/weight and area product for bigger planar cores. The PQ core is a little bit lighter but is penalized by its volume. This is due to its non-low profile core. Others shapes also present interesting characteristics but are limited to smaller core for EQ while the ER one cover the biggest range, from the smallest one (ER9.5) in terms of volume and weight to the biggest one (ER64).

TABLE II: Core size and weight of standard Ferroxcube planar cores - Data

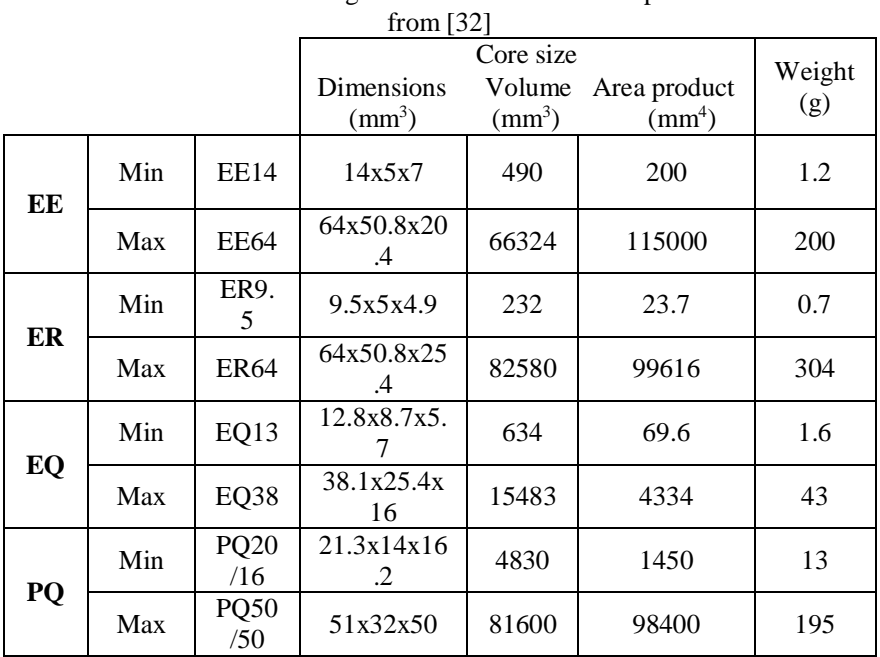


One can note that combination of two $\mathrm{E}$ is not the only one solution for planar E and EQ core. For these two kind of cores, they can be combined with PLT to reduce volume and weight of the component.

It can be obvious that PMC are more interesting to achieve higher power integration as compared to conventional magnetic shapes. Nevertheless, an example of comparison is given in Table III and Table IV. Those tables compare smallest and biggest EE planar cores supplied by [32] and their equivalent in conventional cores with approximately the same area product. On one hand, it can be noted that planar cores are lighter and have less volume. On the other hand, they have higher surface/volume ratio. These characteristics make them better candidate not only for cooling but also for increasing the power density for a same given power value.

TABLE III: Planar vs conventional core size of same area product - Smallest

\begin{tabular}{|c|c|c|} 
planar core available in [32] \\
\cline { 2 - 3 } & Planar core & $\begin{array}{c}\text { Conventional } \\
\text { core }\end{array}$ \\
\cline { 2 - 3 } & E14 & EFD15 \\
\hline Area product $\left(\mathrm{mm}^{4}\right)$ & 200 & 222 \\
\hline Effective area $\left(\mathrm{mm}^{2}\right)$ & 14.3 & 15 \\
\hline Set weight $(\mathrm{g})$ & 1.2 & 2.8 \\
\hline Material volume $\left(\mathrm{mm}^{3}\right)$ & 300 & 510 \\
\hline External volume Vext $\left(\mathrm{mm}^{3}\right)$ & 490 & 1046 \\
\hline External surface for cooling $S_{e x t}\left(\mathrm{~mm}^{2}\right)$ & 70 & 69.75 \\
\hline Ratio $\left(S_{e x t} / V_{e x t}\right)\left(\mathrm{mm}^{-1}\right)$ & 0.14 & 0.066 \\
\hline
\end{tabular}

TABLE IV: Planar vs conventional core size of same area product - Biggest planar core available in [32]

\begin{tabular}{|c|c|c|}
\multicolumn{2}{c|}{} & Planar core available in $[32]$ \\
\cline { 2 - 3 } & Planar core & $\begin{array}{c}\text { Conventional } \\
\text { core }\end{array}$ \\
\cline { 2 - 3 } & E64 & E55 \\
\hline Area product $\left(\mathrm{mm}^{4}\right)$ & 115000 & 117000 \\
\hline Effective area $\left(\mathrm{mm}^{2}\right)$ & 519 & 420 \\
\hline Set weight $(\mathrm{g})$ & 200 & 260 \\
\hline Material volume $\left(\mathrm{mm}^{3}\right)$ & 40700 & 52000 \\
\hline External volume Vext $\left(\mathrm{mm}^{3}\right)$ & 66324 & 77275 \\
\hline External surface for cooling Sext $\left(\mathrm{mm}^{2}\right)$ & 3200 & 1375 \\
\hline Ratio $($ Sext/Vext $)\left(\mathrm{mm}^{-1}\right)$ & 0.048 & 0.017 \\
\hline
\end{tabular}

If PMC frequency and power level are restricted to specific ranges, temperature and magnetic core can also act as limiting parameters. Indeed, one of the main drawbacks of planar transformers is their limited maximum area product for fixed core shapes supplied by manufacturers.

Magnetic material has an important influence. This parameter is linked to the magnetic performances of the component but also to the thermal characteristic. For a given switching frequency, magnetic material is selected to obtain specific and maximal value of magnetizing inductance. Generally, manufacturers give a tolerance of 20 to $25 \%$ on magnetic characteristics of ferrite cores. An air gap can then be added to control the magnetizing value and to avoid core saturation in case of converter control imbalance. Choosing to add an air-gap leads to problems as fringing flux that can create supplementary losses. Conductors have to be placed far away from air gap [36] to reduce those additional eddy currents generated by this fringing flux.

\section{Windings' Technology}

As previously said, planar windings are either made of PCB or copper foil. Sometimes Litz wire can also be used as in classical high frequency wounded magnetics. Fig. 6 presents two examples of planar transformer. The first one (Fig.6a) is a simple 2-layer PCB planar transformer. The second one (Fig.6b) is an 8-layer copper foil planar transformer.

The choice of conductor's size is linked to several parameters: the desired DC current density, the skin depth (2) calculated at the operating switching frequency including harmonics and the eddy currents in the conductors as known as proximity effect. Usually, copper thickness is quite thin due to technology but also in order to limit those eddy currents in layers. As a consequence, planar windings are generally made of multiple layers connected in parallel to support high current. The copper winding does not fill the core window and generally leads to low filling factor.

$$
\delta=\sqrt{\frac{\rho}{\pi \cdot f \cdot \mu}}
$$

With $f$ is the operating frequency, $\mu$ the permeability, and $\rho$ the copper resistivity.

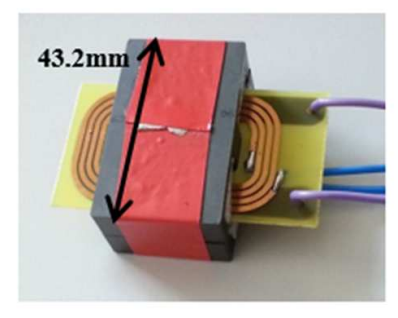

(a)

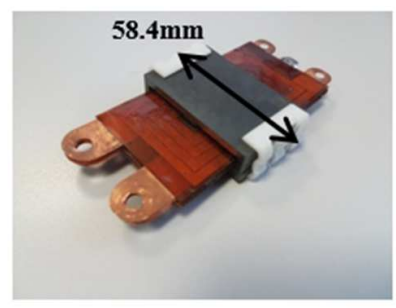

(b)
Fig. 6. Planar technology: (a) PCB (b) copper foil

Multilayer PCB fits well with manufacturing process and automated mass production. The copper thicknesses as well as the insulation between conductors are fixed by standard manufacturing techniques. Moreover these thicknesses are the same for primary and secondary windings. Then, these characteristics limit the flexibility to optimize the design of multilayer PCB planar transformer. Transformer can be integrated directly in converter's PCB but this specific case is limited to small power applications. For transformer designed for some hundreds of watts and more, it is preferred to design a specific multilayer $\mathrm{PCB}$ for the winding transformer. Multilayer PCB needs vias to connect different layers. This creates additional eddy currents and hotspot inside the windings [36][37]. Finally, multilayer PCB does not allow easy insertion of a magnetic layer to increase potentially the leakage energy and so the leakage inductance [38].

For copper foil planar components, windings' conductors are cut inside foil whose thickness can be chosen differently for primary and secondary. Insulation between layers is made with kapton foil, for example, also cut to be sized for planar magnetic core. Such winding technology usually allows more current for power transformer because of the greater thickness that leads to bigger conductors' across section. As opposed to multilayer PCB, a leakage layer can be added easily between layers. However, a problem still remains, dealing with connections of layers that have to be made one by one. 
In both technologies, the maximum number of layers will be limited by the window's core height. Moreover, industrial standards require a minimum space between the conductors and the core and a minimum insulation between conductors of the same layer and conductors of different layers to warranty a level of dielectric rigidity. For every planar component, an attention must also be payed to connections between layers but also between the component and its environment. When they are not well chosen, connections can strongly modify windings and transformer performances.

\section{Modeling PMC: Analytical vs Numerical}

In order to design efficient and optimized planar magnetic components, accurate models are needed. The increase of switching frequency, thanks to new active $\mathrm{SiC}$ and $\mathrm{GaN}$ semiconductors, can be problematic when dealing with modeling.

In literature, analytical models [39][40][41] are generally based on the 1-D magnetic field hypothesis, known as the Dowell hypothesis [42]. Other derivative models close to Dowell's one have been developed to be more accurate when the conductors do not fill the core window width (porosity factor (3) $\eta \leq 0.7$ ) whereas Dowell's model accuracy is proved when $0.7 \leq \eta \leq 1$ [43]. This porosity factor is usually higher for traditional high frequency transformer than for planar ones. Note also that porosity factor is different from the filling factor which is the ratio of the total area of conductors on the core window surface. This filling factor is generally lower for PMC $(<0.4)$ as compared to traditional transformer or self $(>$ $0.75)$. Such approach is also limited with the frequency evolution because of the field hypothesis that becomes inacurate.

$$
\eta=\frac{n \cdot a}{b}
$$

With $n$ the number of turns in a layer, $a$ the conductor width and $b$ the core window width

Some other semi-analytical computational models based on the resolution of Poisson's equation such as PEEC formulation [44] or Roth's method [45] can be used for 2-D transformer's winding cross section. These methods are efficient only when material in rectangular region is homogeneous. Moreover, they require more computational time than analytical ones.

Regarding numerical modeling, 2-D finite element analysis (FEA) are often performed [46][47][48]. 3-D FEA are more complex to achieve and require important computational ressources and time computing. Simplifications are sometimes done, based on the use of 2-D methodology [49] or modelorder reduction (MOR) [50] to shorten resolution time.

Main advantages of 3-D FEA are the possible coupling between electromagnetic and thermal solvers (Maxwell 3D, CFD...) [51]. With such coupling, impact of losses in temperature's distribution is facilitated and can lead to the identification of potential hotspots inside windings, which can be destructive for transformer. This thermal aspect is also an indicator of the PMC's lifetime, focusing on the insulation's aging.

\section{E. Planar selffor EMC}

Apart from the application of filtering inductors in power converter, planar self can also be used to design EMI filters [52][53]. This is possible only when the stress current through the filter does not saturate the core. As a consequence, planar self are more dedicated to common mode (CM) suppression filters than differential one, except adding air gaps through the magnetic core. One can note that CM filters which are coupled, allow compensating the main flux generated by the power current. Some configurations of planar transformers are also interesting while they allow reduction of the EMI conducted noise without adding EMI filters but electrostatic screen between conductive layers [54]. For MEA, these Electromagnetic compatibility (EMC) aspects must be taken into account by designers to meet aeronautical standards such as DO-160 and it begins with qualification tests [55].

\section{Planar Magnetics: Key Parameters}

The design of planar magnetic transformer as well as planar self, must consider some key parameters that need to be controlled or tuned to reach good performances for the component and the power converter.

\section{A. Multiphysics Component}

Modeling and analysis phenomena inside PMC are based on multiple domains of physics, as for traditional high frequency transformer. The main fields involved in the component are: Electrical, electromagnetic, electrostatic and thermal. Fig. 7 presents complete high frequency equivalent circuit for a 2winding transformer, including elements (resistances for losses and inductances) that vary with frequency as well as capacitors for the electrostatic behavior [56][57]. Generally, engineers design transformers to have low losses and low leakage inductance, but capacitances are rarely considered. However, the reduction of the leakage inductance will be made at the expense of parasitic capacitance which will increase. Both aspects are coupled through the thickness of the dielectric material. Different methods can be used to reduce winding capacitances such as using thicker dielectric or inserting a grounded electrostatic screen, but, presently, no method allow reducing both leakage inductance and winding capacitances [17]. In some designs, these parasitic aspects are desired and even enhanced, especially for $L L C$ power converters.

These electromagnetic and electrostatic aspects are effective to represent the equivalent electric circuit of planar transformer, but this one does not include thermal behavior which is linked to transformer's geometry and boundary conditions. Same equivalent circuit (Fig. 7) can be obtained for 3-winding transformer and more generally for n-winding transformers. Such circuit is a really interesting tool that can be included in circuit software. 


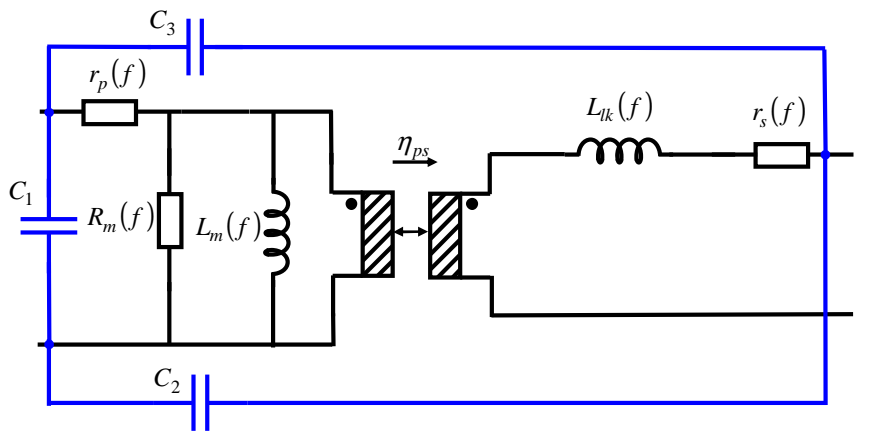

Fig. 7. High frequency equivalent circuit of a planar transformer

The focus is now on some design rules and modeling aspects which must be considered when dealing with planar transformers.

\section{B. Losses and Thermal performances}

Copper losses are a major topic in high frequency power electronic transformer. As mentioned before, copper losses can be evaluated based on analytical formulae or using 2-D and 3-D FEA. Skin and proximity effects increase with frequency and thus create more losses and heat to dissipate.

In high frequency, current densities are concentrated in the corner of the rectangular conductors (i.e PCB or copper foil). Fig. 8 presents current density repartition along a $7 \times 0.5 \mathrm{~mm}^{2}$ conductor for different frequencies and for a sinusoidal excitation. Moreover, planar rectangular conductors are sized thin to limit eddy current effects. In order to withstand enough current, conductors have to be connected in parallel. It has been shown in [58] that even with such connections, high frequency currents are not distributed uniformly between layers. One solution to reduce these high frequency effects, and thus the $\mathrm{AC}$ equivalent resistance of transformer, is to interleave copper layers.
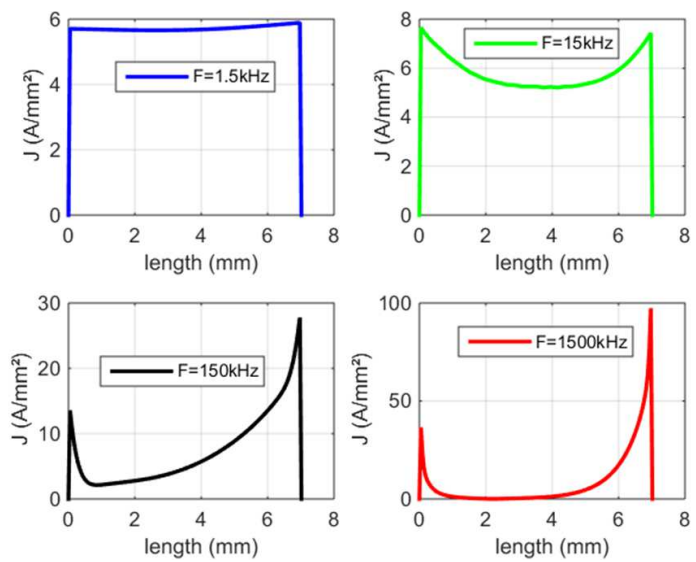

Fig. 8. Example of Eddy current effects on planar rectangular conductors

Regarding copper tracks, it has been shown in [59] that the shape of the windings also have an impact on copper losses in conductors located outside the magnetic core. Mixing different copper shapes (square/round) for primary and secondary windings can improve the reduction of high frequency copper losses.
The other losses to evaluate are the core losses and the dielectric losses, but, the latter are generally considered null regarding the two other types of losses. Core losses can be calculated using data of magnetic material [32], in particular complex permeability. For more precision, magnetic core losses can be calculated with Steinmetz's equation (4) [60] but only when the excitation is sinusoidal. For non-sinusoidal power electronic waveforms, Improved General Steinmetz Equation (iGSE) [61][62] is preferred.

$$
P_{\text {core }}=K_{c} * F_{s w}^{\alpha} * B_{\text {peak }}^{\beta} * V_{c}
$$

Where $K_{c}, \alpha$ and $\beta$ are parameters given by manufacturer's datasheet and $V_{c}$ is the core volume.

As total losses have been determined, the thermal behavior of the planar transformer can be estimated considering these losses as input. The increase of transformer's temperature due to total transformer losses has to be minimized with the use of cooling technology. The thermal behavior can be obtained by performing FEA with numerical tools, but under some assumptions, such as the transfer mode considered, boundary conditions and the exchange coefficient values.

For PMC design, analytical models and tools were recently developed to help designer with the thermal modeling of transformer. In [30], the equivalent thermal resistance variation with ambient temperature and power losses was established analytically. The simplest method to estimate the global temperature rise is based on the following expression:

$$
\Delta T=T_{\max }-T_{\text {amb }}=P_{\text {losses }} \times R_{t h}
$$

With $R_{t h}$ the thermal resistance depending on the transformer's geometry and the thermal coefficient as following for example:

$$
\begin{aligned}
& R_{t h}{ }^{\prime}=\frac{1}{h S_{\text {ext }}} \\
& R_{t h}{ }^{\prime \prime}=\frac{l}{K_{\lambda} S_{c}}
\end{aligned}
$$

With $h$ the thermal coefficient by convection, $K_{\lambda}$ the thermal conductivity, $l$ the characteristic length, $S_{e x t}$ and $S_{c}$ the orthogonal surface of the losses flux.

The equivalent thermal resistance $R_{t h}$ is calculated considering parallel and series associations of different $R_{t h}$ and $R_{t h} "$.

One can note that radiative effect with thermal emissivity is not taken into account, but if so, it can contribute to reduce relatively the temperature rise.

In order to be more precise and to locate potential hotspots inside the component, some computational methods [63] as well as 3D FEA can be performed. In [64][65], temperature inside planar transformer is calculated based on the segmentation of transformer in thermal resistances. The 
authors in [66] proposed an analytical coupled electro-thermal model (1-D) to estimate the transformer's temperature with a good accuracy, but only in transient.

\section{Leakage inductance}

Leakage inductance has a major role in power electronics. Most of applications require low values of leakage inductances because they can induce supplementary losses, stress on active components as well as electromagnetic interference (EMI) due to high frequency voltage oscillations [38][54]. For some applications [67], an important leakage inductance value is useful as in TAB converter in ZVS conditions.

Analytically, the leakage inductance is often calculated using leakage energy (8), based on the 1-D Dowell's assumptions [42] and with windings excited as in (9) so that the flux generated is only linked to the leakage energy.

$$
W_{l k}=\frac{1}{2} L_{l k} I^{2}
$$

With $L_{l k}$ is the leakage inductance which depends on core and conductors dimensions and arrangement and $I$ the current through the considered winding.

$$
I_{p}+\eta \cdot I_{s}=0
$$

Where $I_{p}$ and $I_{s}$ are respectively primary and secondary rms currents, and $\eta$ is the transformer ratio.

Other calculations are performed assuming that the current is uniform across the conductor's section [68]. This hypothesis leads to low frequency inductance values. For higher frequencies, leakage inductance can decrease up to $50 \%$ [69][70] depending on the frequency range chosen. To take into account 3-D effects, FEA can also be performed and are generally more accurate to compute leakage energy.

Interleaving windings (Fig. 9) is the best solution for reducing high frequency copper losses but it also leads to small leakage inductance values.

Some recent studies [71][72] have involved in finding the way to increase the magnetic energy in a core window adding a magnetic layer such as C350 [73] ferrite polymer composite (FPC) for example. Models were developed and results seems pomising since they could improve significantly the leakage inductance but they must also maintain the efficiency. However, this last solution is only valid for planar transformers made of copper foil or several 2-layer PCB assembled together.

\section{Parasitic capacitances}

Parasitic capacitance is also a topic of huge interest in high frequency power electronic converters. Transformers' capacitances exist between different winding's layers. Different electrostatic representations exist but each one is linked to the electrostatic energy stored in the component [57] depending on the number of independent voltage across the component: 3 for a 2-winding transformer (Fig. 7) and 6 for a 3-winding transformer. These capacitances cause resonance, vibration and additional losses in the transformer. That effect could be desired in some resonant converters such as LLC converters [73] but it could also create additional losses while coupling to a consequent leakage inductance [74]. Finally, it could be dangerous for the reliability of the converter. Parasitic capacitances are also paths for common mode currents inducing conducted EMI noises. This phenomenon is more important in circuit where the voltage dynamics are important as in the application presented in Fig. 3 where HVDC SiC MOSFETs can switch up to 650V (Table I) within tens of nanoseconds.

Some capacitances between two layers can be determined with the expression of a plan capacitor assuming there is no voltage drop in a same layer of conductors. With a complete component, including multiple layers and magnetic core, the analytical calculations of parasitic capacitances becomes quickly complex. Even if some models have been developed based on Electric Field Decomposition Method [75] or Green's functions [76], such computation is cumbersome and FEA will be preferred to extract capacitance matrix. Moreover, in transformers with distributed turns between windings, conductors of the same layer should be spaced as far as possible to enhance the fringing effect of the electric field, which reduces the stray capacitance [77] by reducing the electrostatic energy between two parallel plate conductors.

\section{ApPlication Design: From AREA PRoduct to THERMAL BEHAVIOR}

In order to illustrate previous topics, an example of planar transformer design is developed. In the following, a design for the TAB 3-winding transformer (Fig.3) is thus detailed. This transformer has a maximum power of $P_{\max }=4.5 \mathrm{~kW}$ and a switching frequency of $F_{s w}=70 \mathrm{kHz}$. Using expression of area product [78], the size of the core can be determined with the expression (10).

$$
A_{p}=A_{w} \times A_{c}=\frac{P_{\max }}{K_{f} K_{u} B_{p e a k} F_{s w} J_{w}}
$$

With $A_{w}$ the winding window area, $A_{c}$ the core window area, $K_{f}=4$ for a non-sinusoidal excitation, $K_{u}$ is the utilization factor of the window by conductors, $B_{m}$ and $J_{w}$ are the maximum magnetic induction and the primary current density, respectively.

The factor $K_{u}$ has a maximum value of 0.2 for planar conductors [79]. In our design, $K_{u}$ is set to 0.14 . The peak induction is assumed to $B_{\text {peak }}=130 \mathrm{mT}$ in order to avoid the core saturation and the DC current density is fixed $J_{w}=8 A / \mathrm{mm}^{2}$. It comes $A_{p} \approx 110000 \mathrm{~mm}^{4}$, according to Table II, this area product matches with the biggest sizes of planar cores. To achieve the best power density, the core chosen is the EE64.

With this core size, conductors' dimensions can be set up 
taking into account a minimal distance between conductors and core to ensure dielectric insulation. In order to have a good transformer's efficiency, full interleaved windings (Fig. 9) are fixed to reduce the resistive factor $F_{r}(11)$ :

$$
R_{A C}(f)=F_{r}(f) \cdot R_{D C}
$$

One of the possible transformer's configurations (Fig. 9) is made of 18-layer PCB with a copper thickness of $0.21 \mathrm{~mm}$ and a width of $4 \mathrm{~mm}$ for primary winding to achieve $J_{w}$ fixed in (10). Primary and secondary windings have the same thickness because of PCB manufacturing constraints. Each winding is made of six layers; the secondary windings are large enough to limit their DC current density under $20 \mathrm{~A} / \mathrm{mm}^{2}$, which is the limit we assumed for a better thermal dissipation. With the conductors' arrangement chosen, the utilization factor is $K_{u}=0.137$, which is closed to the assumed value.

All layers are separated by FR-4 epoxy with a thickness of $0.25 \mathrm{~mm}$. Primary conductors on the same layer have an insulation of $0.5 \mathrm{~mm}$.

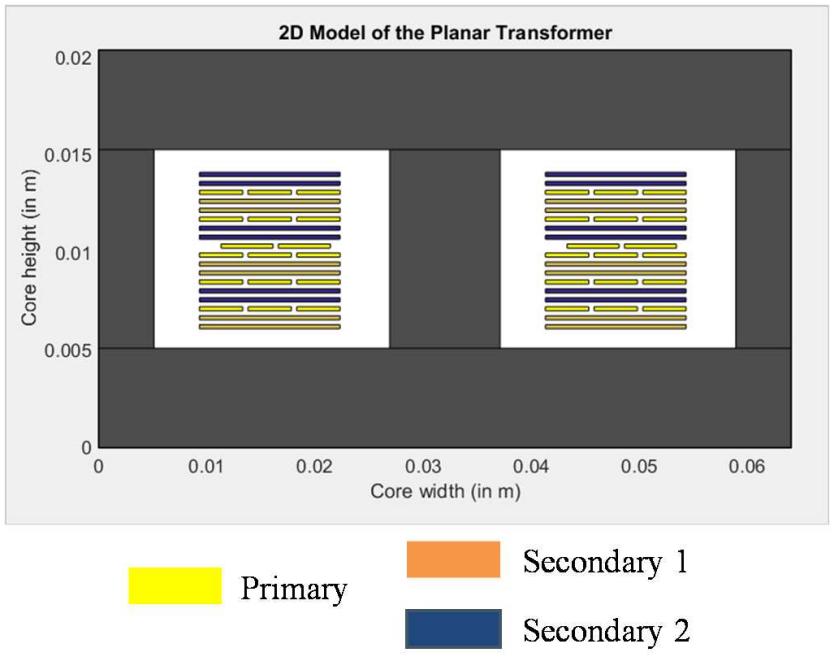

Fig. 9. 2D representation of the planar transformer

To evaluate high frequency copper losses with the arrangement in Fig. 9, 1-D analytical modeling is used on a wide frequency range $[10 \mathrm{kHz} ; 1 \mathrm{MHz}$. Equation (12) is a simplification of the resistive factor, in literature [42], for plate conductors. Skin effect (first term in (12)) and proximity effect (second term in (12)) can be expressed as following:

$F_{r}=X\left[\frac{e^{2 X}-e^{-2 X}+2 \sin (2 X)}{e^{2 X}+e^{-2 X}-2 \cos (2 X)}+\frac{2}{3}\left(m^{2}-1\right) \frac{e^{X}-e^{-X}-2 \sin (X)}{e^{2 X}+e^{-2 X}+2 \cos (2 X)}\right]$

With $X$ defined in (13) and $m$ the number of layers in a winding portion.

$$
X=\frac{h}{\delta}
$$

With $h$ the thickness of the conductor and $\delta$ the skin depth expressed in (2).
A similar expression is used to model the decrease of the leakage inductance from low frequency to high frequency [42].

The DC resistances can easily be expressed knowing the windings' dimensions (14). Finally, the windings' AC resistances can be calculated based on (11), (12) and (14). Fig. 10 presents $\mathrm{AC}$ resistances for the primary and one secondary winding.

$$
R_{D C}=\frac{\rho}{S} * M T L^{*} N
$$

Where $N$ is the turn's number, MTL is the mean turn length and $S$ the current cross-section.

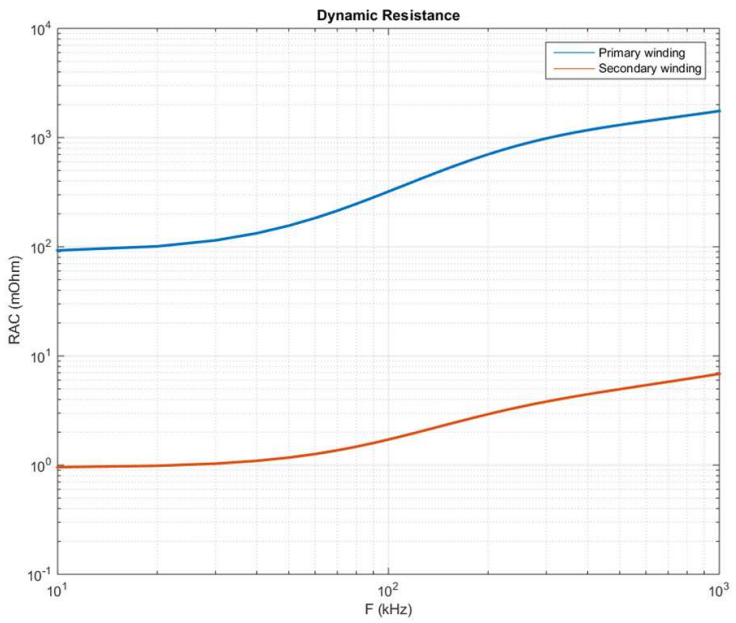

Fig. 10. Analytical winding AC resistances

Resistive factor $F_{r}$ (11) (i.e. ratio of $R_{A C}$ to $R_{D C}$ ) for primary winding in series is between 2 and 3 for a fully interleaved transformer with frequency between $[50 \mathrm{kHz}$; $150 \mathrm{kHz}$ ] but could be higher than 10 for non-interleaved windings. It can be noted that for secondary winding, made of one large conductor per layer, resistive factor is generally higher than 4, especially when secondary layers are put in parallel. Then, depending on the cases, the AC copper losses could be well distributed between layers.

To estimate the temperature rise of the transformer, total losses are considered for a sinusoidal excitation. Therefore, in the following example, losses are under-estimated because TAB's waveforms contain harmonics. In the design example, losses due to the sinusoidal voltage are equal to $31 \mathrm{~W}$ and $9 \mathrm{~W}$ for the copper losses and the ferrite core losses, respectively. Fig. 11 presents the resulting temperature's distribution in the planar transformer designed as well as the one obtained for and equivalent conventional transformer. In both cases, the area product is approximately the same (Table IV). For this simulation, a natural convection by air was considered with a coefficient $\mathrm{h}=14 \mathrm{~W} / \mathrm{m}^{2} . \mathrm{K}$ [79], in steady-state and with an ambient temperature of $25^{\circ} \mathrm{C}$. As boundary condition, the bottoms of transformers are considered to be put on a cooling 
heatsink at $70^{\circ} \mathrm{C}$. Same total losses (i.e. $40 \mathrm{~W}$ ) were considered in both cases. To perform 3D-FEA, an equivalent thermal conductivity was calculated according to the transverse direction (15) and according to the normal direction (16). The calculated coefficients are reported in Table V. This table shows that most of thermal exchange made by conduction are in the $\mathrm{X}-\mathrm{Y}$ plane.

$$
\begin{aligned}
K_{X Y}= & \frac{\sum_{i=1}^{M} h_{i} \times k_{i}}{\sum_{i=1}^{M} h_{i}}=\frac{N_{c u} \times h_{c u} \times k_{c u}+N_{i n s} \times h_{i n s} \times k_{i n s}}{N_{c u} \times h_{c u}+N_{i n s} \times h_{i n s}} \\
K_{Z}= & \frac{\sum_{i=1}^{M} h_{i}}{\sum_{i=1}^{M} \frac{h_{i}}{k_{i}}}=\frac{N_{c u} \times h_{c u}+N_{i n s} \times h_{i n s}}{N_{c u} \times \frac{h_{c u}}{k_{c u}}+N_{i n s} \times \frac{h_{i n s}}{k_{i n s}}}
\end{aligned}
$$

With $N_{c u}$ and $h_{c u}$ the number of copper layers and their thickness, $N_{\text {ins }}$ and $h_{\text {ins }}$ are the number of insulating layers and their thickness, respectively.

TABLE V: Equivalent thermal conductivity

\begin{tabular}{|c|c|}
\cline { 2 - 2 } \multicolumn{1}{c|}{} & Thermal conductivity $\left(\mathrm{W} \cdot \mathrm{m}^{-1} \cdot \mathrm{K}^{-1}\right)$ \\
\hline Copper & 380 \\
\hline FR-4 & 0.25 \\
\hline Core & 5 \\
\hline Transverse $K_{X Y}$ & 174 \\
\hline Normal $K_{Z}$ & 0.46 \\
\hline
\end{tabular}

As it can be seen in Fig. 11, the maximum temperature in the planar transformer is lower than the conventional one. It is principally due to the surface/volume ratio which is higher for the planar technology (Table IV) and hence, its equivalent thermal resistance is lower. This is an important result because it allows weight savings on heatsink and so a better power integration.

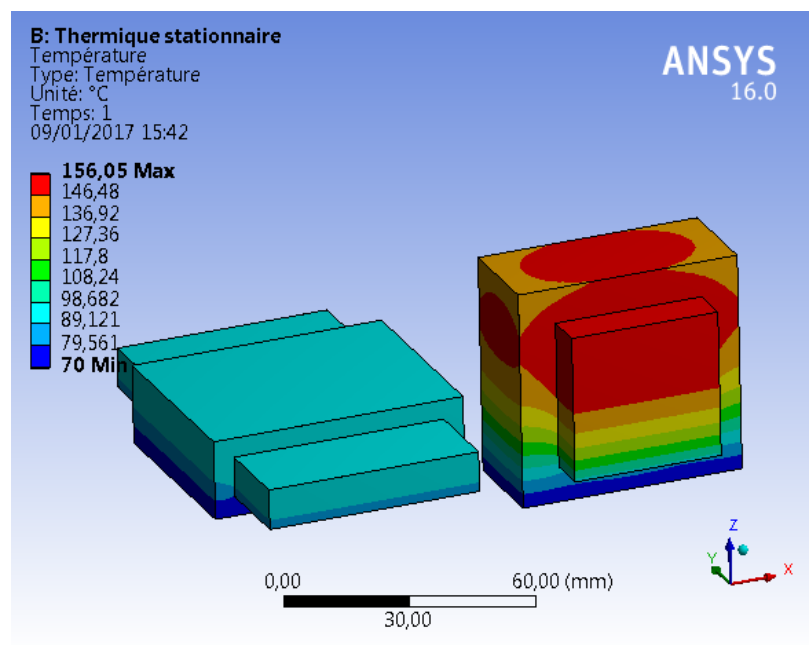

Fig. 11. Temperature distribution in planar vs conventional transformer
Regarding leakage inductances, their analytical values are plotted in Fig. 12 for both secondary windings. Both leakage inductances are close. This can easily be explained by the symmetrical configuration of the arrangement (Fig. 9). Their equivalent inductance in primary winding is about $0.5 \mu \mathrm{H}$ in low frequency, which is very low, and lower again in high frequency (especially $70 \mathrm{kHz}$ which is the switching frequency). This value is not enough according to the desired value $30 \mu \mathrm{H}$ (Table I). Then, this value should be enhanced without largely decreasing transformer's performances. As mentionned in section II.C, an external self (for example from [80]) can be added in series with the windings. Another solution is to add bus bar on secondary windings' connections considering about $10 \mathrm{nH} / \mathrm{cm}$ loop inductance.

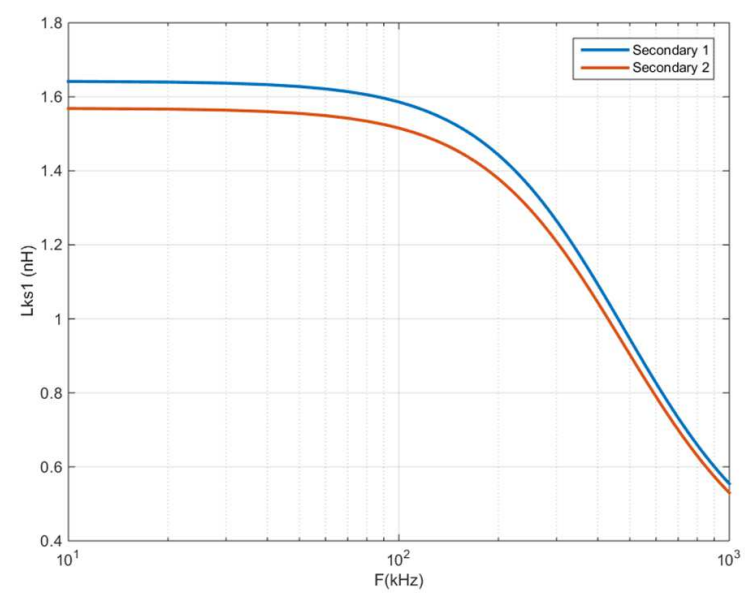

Fig. 12. Analytical leakage inductances from secondary windings

This short example has helped to highlight the link between some of planar transformer's parameters: Design, conductors' layout, losses and leakage inductances. Of course, this design is not complete and could be extended and deepened in order to optimize a planar transformer prototype.

\section{CONCLUSION}

In this paper, challenges and issues on planar magnetic components for MEA have been presented, based on the example of a specific DC/DC converter. Potential benefits of PMC in aircrafts have been highlighted, as well as drawbacks that have to be limited. PMC's key parameters to be optimized have been presented to improve the power converter performances.

Some models were reviewed and discussed with the objective of helping designers to tune or, at least, to control parameters of planar transformers. An example of a high frequency planar transformer was designed and compared to a high frequency conventional transformer, highlighting the planar technology's interest.

Finally, because they can reach higher power densities with better thermal behavior, these planar magnetic components are going to be increasingly used for the MEA in aeronautics as well as for the EV in automotive. 


\section{ACKNOWLEDGMENT}

This work is part of the French project GENOME involved in MEA with the support of Thales Avionics Electrical Systems S.A.S.

\section{REFERENCES}

[1] I. O. Hockmeyer, "The generation and regulation of electric power in aircraft: a survey of design features of generators and their control," $J$. Inst. Electr. Eng. - Part II Power Eng., vol. 93, no. 31, p. 2-, Feb. 1946.

[2] B. Sarlioglu and C. T. Morris, "More Electric Aircraft: Review, Challenges, and Opportunities for Commercial Transport Aircraft," IEEE Trans. Transp. Electrification, vol. 1, no. 1, pp. 54-64, Jun. 2015.

[3] “About Clean Sky 2 | Clean Sky." [Online]. Available: http://www.cleansky.eu/content/homepage/about-clean-sky-2. [Accessed: 02-Sep-2016].

[4] "CORAC Aéro Recherche - Aéronautique Civile - Le CORAC est le Conseil pour la Recherche Aéronautique Civile. Suivez l'actualité de la recherche du secteur de l'aéronautique civile Français.," CORAC Aéro Recherche - Aéronautique Civile. [Online]. Available: http://aerorecherchecorac.com/.

[5] X. Roboam, "New trends and challenges of electrical networks embedded in "more electrical aircraft"," in 2011 IEEE International Symposium on Industrial Electronics, 2011, pp. 26-31.

[6] A. Tenconi and P. W. Wheeler, "Introduction to the Special Section on The More Electric Aircraft: Power Electronics, Machines, and Drives," IEEE Trans. Ind. Electron., vol. 59, no. 9, pp. 3521-3522, Sep. 2012.

[7] F. Gao and S. Bozhko, "Modeling and Impedance Analysis of a Single DC Bus-Based Multiple-Source Multiple-Load Electrical Power System," IEEE Trans. Transp. Electrification, vol. 2, no. 3, pp. 335346, Sep. 2016.

[8] M. T. E. Heinrich, F. Kelch, P. Magne, and A. Emadi, "Regenerative Braking Capability Analysis of an Electric Taxiing System for a Single Aisle Midsize Aircraft," IEEE Trans. Transp. Electrification, vol. 1, no. 3, pp. 298-307, Oct. 2015.

[9] X. Roboam, B. Sareni, and A. D. Andrade, "More Electricity in the Air: Toward Optimized Electrical Networks Embedded in MoreElectrical Aircraft,” IEEE Ind. Electron. Mag., vol. 6, no. 4, pp. 6-17, décembre 2012.

[10] R. T. Naayagi, "A review of more electric aircraft technology," in 2013 International Conference on Energy Efficient Technologies for Sustainability (ICEETS), 2013, pp. 750-753.

[11] M. H. Taha, "Power electronics for aircraft application," in 1999/059), IEE Colloquium on Power Electronics for Demanding Applications (Ref. No, 1999, pp. 7/1-7/4.

[12] T. Bensalah and P. Thalin, "Integrated Modular Power Electronics: Achievements and Challenges," presented at the IMPEC MEA2015, Toulouse, France, 2015

[13] P. Asfaux and J. Bourdon, "Development of a $12 \mathrm{~kW}$ isolated and bidirectional DC-DC Converter dedicated to the More Electrical Aircraft: The Buck Boost Converter Unit (BBCU)," in PCIM Europe 2016; International Exhibition and Conference for Power Electronics, Intelligent Motion, Renewable Energy and Energy Management, 2016, pp. 1-8.

[14] W. G. Homeyer et al., "Advanced power converters for More Electric Aircraft applications," in IECEC 96. Proceedings of the 31st Intersociety Energy Conversion Engineering Conference, 1996, vol. 1, pp. 137-142 vol.1.

[15] J. Bourdon, P. Asfaux, and A. M. Etayo, "Review of power electronics opportunities to integrate in the more electrical aircraft," in 2015 International Conference on Electrical Systems for Aircraft, Railway, Ship Propulsion and Road Vehicles (ESARS), 2015, pp. 1-6.

[16] D. S. Stephens, "Lightweight aircraft transformers," Electr. Eng., vol. 69, no. 2, pp. 156-156, février 1950.

[17] Z. Ouyang and M. A. E. Andersen, "Overview of Planar Magnetic Technology; Fundamental Properties,” IEEE Trans. Power Electron., vol. 29, no. 9, pp. 4888-4900, Sep. 2014.

[18] Y. Deng, S. Y. Foo, and I. Bhattacharya, "Regenerative electric power for More Electric Aircraft," in IEEE SOUTHEASTCON 2014, 2014, pp. 1-5.
[19] M. Tariq et al., "Battery integration with more electric aircraft DC distribution network using phase shifted high power bidirectional DCDC converter," in 2015 IEEE PES Asia-Pacific Power and Energy Engineering Conference (APPEEC), 2015, pp. 1-5.

[20] A. Eid, H. El-Kishky, M. Abdel-Salam, and T. El-Mohandes, "Modeling and characterization of an aircraft electric power system with a fuel cell-equipped APU connected at HVDC bus," in 2010 IEEE International Power Modulator and High Voltage Conference, 2010, pp. 639-642.

[21] J. L. Duarte, M. Hendrix, and M. G. Simoes, "Three-Port Bidirectional Converter for Hybrid Fuel Cell Systems," IEEE Trans. Power Electron., vol. 22, no. 2, pp. 480-487, Mar. 2007.

[22] F. Krismer, "Modeling and Optimization of Bidirectional Dual Active Bridge DC-DC Converter Topologies,” ETH ZURICH, Zurich, 2010.

[23] J. Everts, F. Krismer, J. V. den Keybus, J. Driesen, and J. W. Kolar, "Optimal ZVS Modulation of Single-Phase Single-Stage Bidirectional DAB AC-DC Converters," IEEE Trans. Power Electron., vol. 29, no. 8, pp. 3954-3970, août 2014.

[24] S. Baek, S. Roy, S. Bhattacharya, and S. Kim, "Power flow analysis for 3-port 3-phase dual active bridge $\mathrm{dc} / \mathrm{dc}$ converter and design validation using high frequency planar transformer," in 2013 IEEE Energy Conversion Congress and Exposition (ECCE), 2013, pp. 388 395.

[25] H. Tao, A. Kotsopoulos, J. L. Duarte, and M. A. M. Hendrix, "Transformer-Coupled Multiport ZVS Bidirectional DC-DC Converter With Wide Input Range," IEEE Trans. Power Electron., vol. 23, no. 2, pp. 771-781, Mar. 2008.

[26] C. Zhao, S. D. Round, and J. W. Kolar, "An Isolated Three-Port Bidirectional DC-DC Converter With Decoupled Power Flow Management," IEEE Trans. Power Electron., vol. 23, no. 5, pp. 24432453, Sep. 2008.

[27] X. Margueron and J. P. Keradec, "Design of Equivalent Circuits and Characterization Strategy for n-Input Coupled Inductors," IEEE Trans. Ind. Appl., vol. 43, no. 1, pp. 14-22, Jan. 2007.

[28] R. A. Mastromauro, M. C. Poliseno, S. Pugliese, F. Cupertino, and S. Stasi, "SiC MOSFET Dual Active Bridge converter for harsh environment applications in a more-electric-aircraft," in 2015 International Conference on Electrical Systems for Aircraft, Railway, Ship Propulsion and Road Vehicles (ESARS), 2015, pp. 1-6.

[29] B. W. Carsten, "The low leakage inductance of planar transformers; fact or myth?," in Sixteenth Annual IEEE Applied Power Electronics Conference and Exposition, 2001. APEC 2001, 2001, vol. 2, pp. 1184-1188 vol.2.

[30] R. Bakri, J. S. N. T. Magambo, X. Margueron, P. Le Moigne, and N. Idir, "Planar transformer equivalent thermal resistance variation with ambient temperature and power losses," presented at the EPE'16 ECCE Europe, Karlsruhe, Germany, 2016.

[31] C. W. T. McLyman, Transformer and Inductor Design Handbook, 3rd ed. Boca Raton. FL, USA: CRC Press, 2004.

[32] "Ferroxcube." [Online]. Available: http://www.ferroxcube.com/FerroxcubeCorporateReception/index.do? action=gotoPage\&pageType=_en. [Accessed: 14-Sep-2016].

[33] "Ceramic Magnetics Homepage." [Online]. Available: http://www.cmi-ferrite.com/. [Accessed: 14-Sep-2016]

[34] "Ferrites and Accessories | Products | TDK Product Center." [Online]. Available: https://product.tdk.com/info/en/products/ferrite/index.html. [Accessed: 14-Sep-2016].

[35] Y.-H. Shin, Y.-S. Oh, K.-S. Ahn, and C.-S. Kim, “Adapter design using planar transformer for aircraft," in Telecommunications Energy Conference, 2009. INTELEC 2009. 31st International, 2009, pp. 1-5.

[36] K. Zhang et al., "Modeling and design optimization of planar power transformer for aerospace application," in Aerospace Electronics Conference (NAECON), Proceedings of the IEEE 2009 National, 2009, pp. 116-120.

[37] C. Ropoteanu, N. D. Codreanu, and C. Ionescu, "Thermal investigation of a planar core power transformer," in 201639 th International Spring Seminar on Electronics Technology (ISSE), 2016, pp. 112-115.

[38] Z. Ouyang, O. C. Thomsen, and M. A. E. Andersen, "Optimal Design and Tradeoff Analysis of Planar Transformer in High-Power DC-DC Converters," IEEE Trans. Ind. Electron., vol. 59, no. 7, pp. 28002810, Jul. 2012.

[39] R. Prieto, J. Á. Oliver, J. A. Cobos, and M. Christini, "Magnetic Component Model for Planar Structures Based on Transmission 
Lines,” IEEE Trans. Ind. Electron., vol. 57, no. 5, pp. 1663-1669, mai 2010.

[40] M. Chen, M. Araghchini, K. K. Afridi, J. H. Lang, C. R. Sullivan, and D. J. Perreault, "A Systematic Approach to Modeling Impedances and Current Distribution in Planar Magnetics," IEEE Trans. Power Electron., vol. 31, no. 1, pp. 560-580, Jan. 2016.

[41] L. A. R. Tria, D. Zhang, and J. E. Fletcher, "Implementation of a Nonlinear Planar Magnetics Model," IEEE Trans. Power Electron., vol. 31, no. 9, pp. 6534-6542, Sep. 2016.

[42] P. L. Dowell, "Effects of eddy currents in transformer windings," Proc. Inst. Electr. Eng., vol. 113, no. 8, pp. 1387-1394, Aug. 1966.

[43] A. Reatti and M. K. Kazimierczuk, "Comparison of various methods for calculating the AC resistance of inductors," IEEE Trans. Magn., vol. 38, no. 3, pp. 1512-1518, May 2002.

[44] H. Bui-Ngoc, H. Chazal, Y. Lembeye, J.-P. Keradec, and J.-L. Schanen, "New $\mu$ PEEC formulation for modeling 2D core transformer. Principles, academic and industrial applications," in 2013 Twenty-Eighth Annual IEEE Applied Power Electronics Conference and Exposition (APEC), 2013, pp. 553-558.

[45] P. Hammond, "Roth's method for the solution of boundary-value problems in electrical engineering," Proc. Inst. Electr. Eng., vol. 114, no. 12, pp. 1969-1976, Dec. 1967.

[46] W. Chen, Y. Yan, Y. Hu, and Q. Lu, "Model and design of PCB parallel winding for planar transformer," IEEE Trans. Magn., vol. 39, no. 5, pp. 3202-3204, Sep. 2003.

[47] A. D. Podoltsev, I. N. Kucheryavaya, and B. B. Lebedev, “Analysis of effective resistance and eddy-current losses in multiturn winding of high-frequency magnetic components," IEEE Trans. Magn., vol. 39, no. 1, pp. 539-548, Jan. 2003.

[48] "Finite Element Method Magnetics: HomePage." [Online]. Available: http://www.femm.info/wiki/HomePage.

[49] J. Aime, B. Cogitore, G. Meunier, E. Clavel, and Y. Marechal, "Numerical Methods for Eddy Currents Modeling of Planar Transformers," IEEE Trans. Magn., vol. 47, no. 5, pp. 1014-1017, mai 2011

[50] L. Taylor, T. Henneron, X. Margueron, Y. Le Menach, and P. Le Moigne, "Model-order reduction of magneto-harmonic problems based on POD: application to planar magnetic components," Eur Phys J Appl Phys, vol. 74, no. 10903, Apr. 2016.

[51] “ANSYS - Simulation Driven Product Development." [Online]. Available: http://www.ansys.comhttp://www.ansys.com/. [Accessed: 14-Sep-2016].

[52] R. Chen, J. D. van Wyk, S. Wang, and W. G. Odendaal, "Improving the Characteristics of integrated EMI filters by embedded conductive Layers," IEEE Trans. Power Electron., vol. 20, no. 3, pp. 611-619, mai 2005 .

[53] W. Tan, C. Cuellar, X. Margueron, and N. Idir, "A High Frequency Equivalent Circuit and Parameter Extraction Procedure for Common Mode Choke in the EMI Filter," IEEE Trans. Power Electron., vol. 28, no. 3, pp. 1157-1166, Mar. 2013.

[54] M. Pahlevaninezhad, D. Hamza, and P. K. Jain, “An Improved Layout Strategy for Common-Mode EMI Suppression Applicable to HighFrequency Planar Transformers in High-Power DC/DC Converters Used for Electric Vehicles," IEEE Trans. Power Electron., vol. 29, no. 3, pp. 1211-1228, Mar. 2014.

[55] T. He and B. Kuhlman, "Investigation of test methods for DO-160 qualification tests," in 2003 IEEE International Symposium on Electromagnetic Compatibility, 2003, vol. 1, pp. 120-123 vol.1.

[56] X. Margueron and J. P. Keradec, "Identifying the Magnetic Part of the Equivalent Circuit of -Winding Transformers," IEEE Trans. Instrum. Meas., vol. 56, no. 1, pp. 146-152, février 2007.

[57] A. Schellmanns, J. P. Keradec, J. L. Schanen, and K. Berrouche, "Representing electrical behaviour of transformers by lumped element circuits: a global physical approach," in Conference Record of the 1999 IEEE Industry Applications Conference, 1999. Thirty-Fourth IAS Annual Meeting, 1999, vol. 3, pp. 2100-2107 vol.3.

[58] X. Margueron, A. Besri, Y. Lembeye, and J. P. Keradec, "Current Sharing Between Parallel Turns of a Planar Transformer: Prediction and Improvement Using a Circuit Simulation Software," IEEE Trans. Ind. Appl., vol. 46, no. 3, pp. 1064-1071, mai 2010.

[59] J. S. N. T. Magambo, R. Bakri, X. Margueron, P. L. Moigne, A. Mahe, and T. Bensalah, "Impact of PCB track shape on HF copper losses of planar magnetic components," in 2016 International Symposium on Power Electronics, Electrical Drives, Automation and Motion (SPEEDAM), 2016, pp. 973-978.
[60] C. P. Steinmetz, "On the Law of Hysteresis," Trans. Am. Inst. Electr. Eng., vol. IX, no. 1, pp. 1-64, Jan. 1892.

[61] J. Li, T. Abdallah, and C. R. Sullivan, "Improved calculation of core loss with nonsinusoidal waveforms," in Conference Record of the 2001 IEEE Industry Applications Conference, 2001. Thirty-Sixth IAS Annual Meeting, 2001, vol. 4, pp. 2203-2210 vol.4.

[62] K. Venkatachalam, C. R. Sullivan, T. Abdallah, and H. Tacca, "Accurate prediction of ferrite core loss with nonsinusoidal waveforms using only Steinmetz parameters," in 2002 IEEE Workshop on Computers in Power Electronics, 2002. Proceedings, 2002, pp. 36-41.

[63] C. Buccella, C. Cecati, and F. de Monte, "A computational method of temperature distribution in high frequency planar transformers," in 2011 IEEE International Symposium on Industrial Electronics, 2011, pp. 477-482.

[64] A. Lewaiter and B. Ackermann, "A thermal model for planar transformers," in , 2001 4th IEEE International Conference on Power Electronics and Drive Systems, 2001. Proceedings, 2001, vol. 2, pp. 669-673 vol.2.

[65] M. Rascon, J. Ara, R. Madsen, J. Navas, M. Perez, and F. S. Miguel, "Thermal analysis and modelling of planar magnetic components," in Sixteenth Annual IEEE Applied Power Electronics Conference and Exposition, 2001. APEC 2001, 2001, vol. 1, pp. 97-101 vol.1.

[66] C. Buccella, C. Cecati, and F. de Monte, "A Coupled Electrothermal Model for Planar Transformer Temperature Distribution Computation," IEEE Trans. Ind. Electron., vol. 55, no. 10, pp. 35833590, Oct. 2008.

[67] J. Ferrell, J.-S. Lai, T. Nergaard, X. Huang, L. Zhu, and R. Davis, "The role of parasitic inductance in high-power planar transformer design and converter integration," in Nineteenth Annual IEEE Applied Power Electronics Conference and Exposition, 2004. APEC '04, 2004, vol. 1, pp. 510-515 Vol.1.

[68] X. Margueron, A. Besri, P. Jeannin, J.-P. Keradec, and G. Parent, "Complete Analytical Calculation of Static Leakage Parameters: A Step Toward HF Transformer Optimization,” IEEE Trans. Ind. Appl., vol. 46, no. 3, pp. 1055-1063, mai 2010.

[69] M. A. Bahmani and T. Thiringer, "Accurate Evaluation of Leakage Inductance in High-Frequency Transformers Using an Improved Frequency-Dependent Expression," IEEE Trans. Power Electron., vol. 30 , no. 10 , pp. 5738-5745, Oct. 2015.

[70] Z. Ouyang, J. Zhang, and W. G. Hurley, "Calculation of Leakage Inductance for High-Frequency Transformers," IEEE Trans. Power Electron., vol. 30, no. 10, pp. 5769-5775, Oct. 2015.

[71] J. Zhang, Z. Ouyang, M. Duffy, M. Andersen, and G. Hurley, "Leakage Inductance Calculation for Planar Transformers with a Magnetic Shunt," IEEE Trans. Ind. Appl., vol. PP, no. 99, pp. 1-1, 2014.

[72] W. Tan, X. Margueron, L. Taylor, and N. Idir, "Leakage Inductance Analytical Calculation for Planar Components With Leakage Layers," IEEE Trans. Power Electron., vol. 31, no. 6, pp. 4462-4473, Jun. 2016.

[73] J. Zhang, W. G. Hurley, and W. H. Wolfle, "Design of the planar transformer in llc resonant converters for micro-grid applications," in 2014 IEEE 5th International Symposium on Power Electronics for Distributed Generation Systems (PEDG), 2014, pp. 1-7.

[74] J. Li, Y. Shi, Z. Niu, and D. Zhou, "Modeling, simulation and optimization design of PCB planar transformer," in Proceedings of the Eighth International Conference on Electrical Machines and Systems, 2005. ICEMS 2005, 2005, vol. 3, pp. 1736-1739 Vol. 3.

[75] W. Tan, X. Margueron, and N. Idir, "An analytical method for modeling parasitic capacitances of planar components for EMI filters," EJEE, vol. VOL 16, no. 3/4, pp. pp.425-445, 2013.

[76] W. Tan, X. Margueron, T. Duquesne, and N. Idir, "An Improved Parasitic Capacitance Cancellation Method for Planar Differential Mode Inductor in EMI Filters," in 2012 7th International Conference on Integrated Power Electronics Systems (CIPS), 2012, pp. 1-6.

[77] P. C. F. Chan, C. K. Lee, and S. Y. R. Hui, "Stray capacitance calculation of coreless planar transformers including fringing effects," Electron. Lett., vol. 43, no. 23, Nov. 2007.

[78] W. J. Gu and R. Liu, "A study of volume and weight vs. frequency for high-frequency transformers," in , 24th Annual IEEE Power Electronics Specialists Conference, 1993. PESC'93 Record, 1993, pp. 1123-1129. 
[79] W. G. Hurley and W. H. Wolfle, TRANSFORMERS AND INDUCTORS FOR POWER ELECTRONICS: THEORY, DESIGN AND APPLICATIONS. John Wiley \& Sons Ltd., 2013.

[80] "Coilcraft - RF chip inductors, power inductors, and other magnetics." [Online]. Available: http://www.coilcraft.com/.

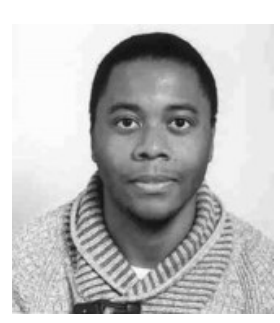

J. Sylvio Ngoua Teu Magambo was born in Libreville, Gabon, in 1990. He reveived the Diploma degree of electrical engineering from the Ecole Nationale Superieure d'Electricite et de Mecanique, Nancy, France, in 2014. He is currently Ph.D. student in electrical engineering at Centrale Lille, Villeneuve d'Ascq, France. His principal fields of research are related to HF modeling, design and optimization of planar magnetic components for aeronautics power converters.

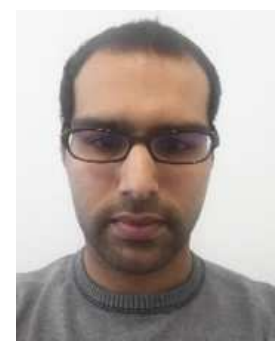

Reda Bakri was born in Morocco, in 1989. He received the Engineering degree from the Ecole Nationale Superieure des Arts et Metiers, Lille, France, in 2014. He is currently Ph.D. student in electrical engineering at Centrale Lille, Villeneuve d'Ascq, France. His works interests are about thermal modeling of passive component and especially planar technology for power electronic converters.

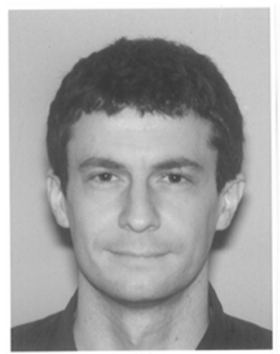

Xavier Margueron (M'09) was born in Chambery, France, in 1980. He received the Diploma degree from the Ecole Nationale Superieure d'Ingenieurs Electriciens de Grenoble, Saint Martin d'Heres, France, in 2003, and the $\mathrm{Ph} . \mathrm{D}$. degree from the Universite Joseph Fourier Grenoble, France, in 2006, both in electrical engineering. Since September 2007, he has been an Associate Professor at Centrale Lille, Villeneuve d'Ascq, France, where he carries out research in the L2EP laboratory. His research interests include modeling and optimization of $\mathrm{HF}$ magnetic passive components for power electronic converters and planar magnetic technology.

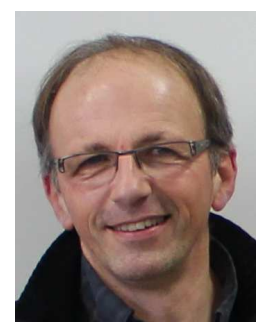

Philippe Le Moigne (M'93) received the Engineering degree from the Institut Industriel du Nord, Lille, France, in 1986, and the Ph.D. degree in electrical engineering from the University of Lille, Lille, in 1990. He is currently a Professor at Centrale Lille in France. He is the Leader of the Power Electronic Research Group of the Laboratoire d'Electrotechnique et d'Electronique de Puissance de Lille. His major fields of interest include hard-switched power converters, especially the control of multilevel topologies for mediumand high-power applications with the aim of high power quality and high efficiency, supercapacitor and battery behaviour associated with specific power converters for electrical applications.

Arnaud Mahe was born in Saint-Nazaire, France, in 1976. He received the Master's Degree in Engineering from CUST, Clermont-Ferrand, France, in 2000.

He worked in different units of the THALES Group in the field of Power Electronics as Research/Design Engineer.
Stéphane Guguen was graduated from the Ecole Nationale Supérieure d'Ingénieur des Etudes et des Techniques d'Armement (ENSIETA), Brest, France, in 1999. He is currently with Thales Avionics Electrical Systems, working as a research and development engineer.

Taoufik Bensalah received different M.S. degrees in Applied Physics, Electronics \& Microelectronics and Business management. He worked more than 15 years in Railways Electric Traction. He joined Thales Electrical System in 2010 as Power Electronics team manager. He's main interest includes advanced technologies for More Electric Aircraft. 